\title{
CARTA fellows' scientific contribution to the African public and population Health Research agenda (2011 to 2018)
}

Jude O. Igumbor ${ }^{1}$, Edna N. Bosire $2^{2^{*}}$ (D, Tariro J. Basera ${ }^{1}$, Dieudonne Uwizeye ${ }^{3}$, Olufunke Fayehun ${ }^{4}$, Hesborn Wao $^{5}$, Ademola Ajuwon ${ }^{6}$, Emmanuel Otukpa ${ }^{5}$, Florah Karimi ${ }^{5}$, Daphney Conco', Evelyn Gitau ${ }^{5}$ and Sharon Fonn ${ }^{1}$

\begin{abstract}
Background: Since its inception in 2009, the Consortium for Advanced Research Training in Africa (CARTA) program has focused on strengthening the capacity of nine African universities and four research centres to produce skilled researchers and scholars able to improve public and population health on the continent. This study describes the alignment between CARTA-supported doctoral topics and publications with the priorities articulated by the African public and population health research agenda.

Methods: We reviewed the output from CARTA PhD fellows between 2011 and 2018 to establish the volume and scope of the publications, and the degree to which the research focus coincided with the SDGs, World Bank, and African Development Bank research priority areas. We identified nine key priority areas into which the topics were classified.

Results: In total, 140 CARTA fellows published 806 articles in peer-reviewed journals over the 8 years up to 2018. All the publications considered in this paper had authors affiliated with African universities, $90 \%$ of the publications had an African university first author and $41 \%$ of the papers have CARTA fellows as the first author. The publications are available in over 6300 online versions and have been cited in over 5500 other publications. About $69 \%$ of the published papers addressed the nine African public and population health research agenda and SDG priority areas. Infectious diseases topped the list of publications (26.8\%), followed by the health system and policy research (17.6\%), maternal and child health (14.7\%), sexual and reproductive health (14.3\%).

Conclusions: Investments by CARTA in supporting doctoral studies provides fellows with sufficient training and skills to publish their research in fields of public and population health. The number of publications is understandably uneven across Africa's public and population priority areas. Even while low in number, fellows are publishing in areas such as non-communicable disease, health financing, neglected tropical diseases and environmental health. Violence and injury is perhaps underrepresented. There is need to keep developing research capacity in partner institutions with low research output by training more PhDs in such institutions and by facilitating enabling environments for research.
\end{abstract}

Keywords: Population and health priorities, Doctoral research, African agenda, Peer review publications

\footnotetext{
* Correspondence: edna.bosire@wits.ac.za

${ }^{2}$ South African Medical Research Council Developmental Pathways for Health Research Unit (DPHRU), School of Clinical Medicine, Faculty of Health

Sciences, University of the Witwatersrand, 27 St Andrews Road, Parktown, Johannesburg, South Africa

Full list of author information is available at the end of the article
}

(c) The Author(s). 2020 Open Access This article is licensed under a Creative Commons Attribution 4.0 International License, which permits use, sharing, adaptation, distribution and reproduction in any medium or format, as long as you give appropriate credit to the original author(s) and the source, provide a link to the Creative Commons licence, and indicate if changes were made. The images or other third party material in this article are included in the article's Creative Commons licence, unless indicated otherwise in a credit line to the material. If material is not included in the article's Creative Commons licence and your intended use is not permitted by statutory regulation or exceeds the permitted use, you will need to obtain permission directly from the copyright holder. To view a copy of this licence, visit http://creativecommons.org/licenses/by/4.0/ The Creative Commons Public Domain Dedication waiver (http://creativecommons.org/publicdomain/zero/1.0/) applies to the data made available in this article, unless otherwise stated in a credit line to the data. 


\section{Background}

Africa has a disproportionate burden of both infectious and non-communicable diseases (NCDs) compared with other world regions [1]. Current disease estimates indicate increases in the incidence of NCDs, including cardiovascular diseases (like hypertension and stroke), cancers, and diabetes, which are now major causes of morbidity and mortality and are projected to overtake infectious diseases by 2030 [2]. This is occurring when most African countries are still struggling to control infectious diseases such as Human Immunodeficiency Virus and Acquired Immunodeficiency Syndrome (HIV and AIDS) and Tuberculosis (TB), due to weak and overburdened health systems [3]; inadequate resources for scaling up proven interventions; poor management of human resources for health; and recurrent natural and man-made disasters and emergencies [4]. Other contributors to the heavy disease burden on the continent include food insecurity, poor access to safe sanitation, the prevalence of indoor pollutants, increased rates of unemployment, violence and forced migration and access to cheap but unhealthy foods [5]. Tackling these challenges and coming up with pragmatic solutions requires robust research $[6,7]$.

This need for local research is occurring when Africa has in the recent past been reported to lag behind other regions in research output - producing less than $1 \%$ of the world's research [8], including research in the fields of population and health $[9,10]$. The under-performance in research in Africa is partly due to inadequate research funding by African governments [11, 12]. During the first African Ministerial Conference on Science and Technology in 2003, participating countries committed to spending at least $1 \%$ of their gross domestic product on research and development by 2010 [12, 13]. Three countries, Malawi, Uganda, and South Africa, had honoured this commitment five years down the line, in 2015 [14]. Other reasons for under-performance include inadequate access to research training [9], poor research infrastructure and technology such as laboratories and computers, insufficient mentorship for junior researchers [11], and limited collaboration or partnerships among research institutions within Africa [10].

There has however been a substantial improvement in the output of researchers in the field of public and population health in many African universities during the past decade $[15,16]$, a development attributed to advancement in the faculties of public and population health in higher education institutions $[16,17]$. Nachega and colleagues [16] reported that between 1991 and 2010, epidemiology and public health research output in the World Health Organization (WHO)/African Region (AFRO) increased from 172 to 1086 peer-reviewed articles per annum, which is a $631 \%$ increase over 19 years. During this period, the most commonly research topics published by researchers from African institutions were on HIV/AIDS (11\%), malaria (9\%), and tuberculosis (7\%), which may be motivated by the articulation of the Millennium Development Goals (MDGs) and increased donor funding in specific disease areas [18].

There have been a number of contributions to the development of research capacity on the continent. While not yet adequate, there has been both national and international investment in higher education in general $[19,20]$. There has also been a commitment to health-related research. The New African Region Health Research Strategy adopted by the African Union Health ministers in 2015, has prioritised public and population health research [21]. Significant investment in health related research capacity building has also taken place, including the African Institutions Initiative [22], and investments made through the Developing Excellence in Leadership, Training and Science (DELTAS) programme [23], as well as the establishment of the Centre for Disease Control (Africa CDC) by the African Union General Assembly in 2015 [24].

As the disease burden changes on the continent, a comprehensive approach is needed to guide health research capacity in the region, and policies and interventions need to be appropriate to local conditions. The conduct and dissemination of good quality research undertaken by African scientists is central to this [25]. We investigated the research output of a cohort of African scholars to assess the degree to which their research is related to the identified African health priorities.

We focused on one initiative for which we had comprehensive data, the Consortium for Advanced Research Training in Africa (CARTA) [26]. Launched in 2009, CARTA initially brought together nine academic and four research institutions from seven countries in Africa, in partnership with selected non-African universities and training institutes. CARTA aims to develop sustainable health research capacity in Africa through training of $\mathrm{PhD}$ fellows in public and population health and promoting research supportive environments. Part of CARTA's strategy for long term sustainability is that staff of participating African consortium institutions are admitted and supported to obtain their $\mathrm{PhD}$, as a way to build and multiply research capacity in the continent [26]. This study describes the publications authored by CARTA supported PhD fellows and compared them to published consensus on African public and population health research agenda of the sustainable development goals (SDGs), World Bank (WB) and Africa Development Bank (AfDB).

\section{Methods}

Study design

A bibliometric search of research output from CARTA $\mathrm{PhD}$ fellows between 2011 and 2018 was conducted to 
establish the volume and scope of the publications. In 2011 there were 20 fellows in the programme and by 2018, 185 fellows had been admitted in the fellowship. We did not include any paper published by the fellows before they were recruited into the program. We compared the content of the publications with research priorities identified by the SDGs, WB and AfDB. A list of public and population health priorities identified by SGD, WB, and AfDB was developed to categorise the CARTA fellows' publication outputs. This process resulted in the nine priority area in which CARTA fellows have published including: (1) infectious diseases, (2) non-communicable diseases (NCDs), (3) mental health, (4) sexual and reproductive health (SRH), (5) maternal and child health $(\mathrm{MCH}),(6)$ health systems and policy, (7) violence and injuries, (8) food security and nutrition and (9) environmental health. Other publications were categorised as "others" and included topics in education, demography, capacity building, pharmacology, microbiology, and occupational health.

\section{Data selection and analysis}

A total of 806 publications were received from the CARTA database maintained by the CARTA secretariat which is hosted by the African Population and Health Research Centre (APHRC), Nairobi, Kenya. The publications were validated for the accuracy of citation by checking each publication online through PubMed, Google Scholar, or ResearchGate databases. In cases where the publications were not available in these sources, the respective CARTA fellow were contacted to verify the full citation of their publications. We omitted study publications that were not peer-reviewed, and publications that could neither be accessed online nor verified as accurate citations by the respective authors contacted. We also excluded publications submitted for review before an individual's CARTA fellowship period because the CARTA intervention would not have contributed to the conceptualization of those specific publications. We further excluded books, theses, editorials, commentaries, and blog publications, as we could not establish whether the publication was a result of a peer-review process.

The study topics were exported into Microsoft Excel for manual validation and classification. For each publication, we also captured the affiliations of the fellows (both the university where they were employed (their home university) and where they are registered for their degree (if this was different from their home institution), the number of online versions of the publication available, and the number of times each publication has been cited in other peer-reviewed publications. We also captured the number of CARTA fellows in each publication, the order of authorships, other funding sources for the studies and the journal's impact factor. The results are presented as proportions and frequencies using a combination of tables and graphical methods.

The focus or main field of research of each study was categorised and then cross-matched with the SDG, World Bank (WB), and African Development Bank (AfDB) Agenda 2063's Goal 3 on Healthy and Wellnourished Citizens for Africa as summarised in Table 1. This was done independently by three reviewers and discrepancies in the classification were discussed and verified by a fourth reviewer.

\section{Results}

\section{Publication pattern}

In total, 140 CARTA fellows enrolled in CARTA program published 806 articles during the period under review. The annual number of peer review articles published by the fellows increased from 11 articles in 2011 to 223 articles in 2018. Figure 1 shows the increase in the number of articles published over time. The publications were available in 6308 online versions and had been cited in 5529 publications (Table 2). The journals that the fellows published in have a median impact factor of 2.10 (Interquartile range (IQR): 1.04-2.78). Given the nature of the programme and our inclusion criteria, all the publications considered in this paper had an author affiliated with an African university, 90\% of the publications had an African university first author and $41 \%$ of the papers have CARTA fellows as the first author. Furthermore, $10 \%$ of the published papers was authored by more than one CARTA fellow. We also found that $70 \%$ of the publications were from fellows affiliated with participating universities in Kenya, Nigeria, and South Africa.

The average number of authors per publication was 5 (SD: 4). The majority of the papers were published by two to five authors (61.5\%), and $34.9 \%$ of the published articles included more than five authors. Fewer publications (3.6\%) had a single author. The median number of

Table 1 Summary of health priorities in which CARTA fellows have published

\begin{tabular}{llll}
\hline Health priorities & SDG & WB & AfDB \\
\hline 1. Infectious diseases & $\checkmark$ & $\checkmark$ & $\checkmark$ \\
2. Non-communicable diseases (NCDs) & $\checkmark$ & & \\
3. Sexual and reproductive health (SRH) & $\checkmark$ & $\checkmark$ & $\checkmark$ \\
4. Maternal and child health (MCH) & $\checkmark$ & $\checkmark$ & $\checkmark$ \\
5. Health Systems and Policy & $\checkmark$ & $\checkmark$ & $\checkmark$ \\
6. Violence and injuries & $\checkmark$ & $\checkmark$ & \\
7. Food security and nutrition & $\checkmark$ & $\checkmark$ & $\checkmark$ \\
8. Mental health and substance abuse & $\checkmark$ & $\checkmark$ & \\
9. Environmental health & $\checkmark$ & $\checkmark$ & $\checkmark$ \\
\hline
\end{tabular}

SDG Sustainable Development Goals; WB World Bank; AfDB African Development Bank 


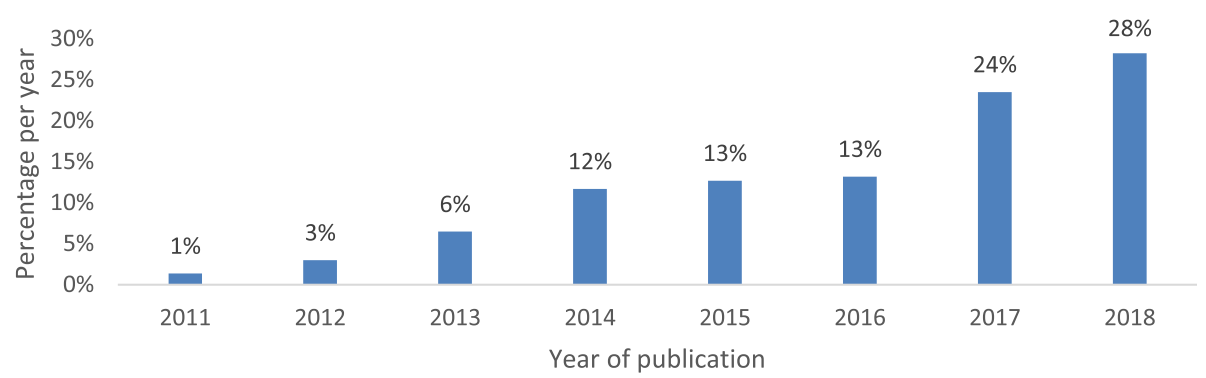

Fig. 1 Percentage distribution of all articles published by CARTA fellows from 2011 to 2018 by year of publication $(N=806)$

publications per fellow per year was 3 (IQR: 2-6). Table 2 also shows that the majority of the publications were quantitative research studies (72\%).

\section{Publication by research area}

About 69\% of the 806 published papers fell into the nine priority areas. Figure 2 shows the papers published in the nine priority areas, the highest proportion of the publications were on infectious diseases with at least one out of four articles published (26.8\%) in this priority area. This was followed by health systems and policy (17.6\%), maternal and child health (14.7\%), sexual reproductive health (14.3\%), and NCDs (10.7\%). A smaller proportion of articles were on contemporary challenges

Table 2 Summary of characteristics of publications and authors

\begin{tabular}{ll}
\hline Summary characteristics of publications and authors. \\
\hline Total number of publications & 806 \\
Total number of fellows & 140 \\
Median impact factor of the journals & 2.10 (IQR: 1.04- \\
& $2.78)$. \\
Number of online versions of published papers & 6308 \\
Number of times all papers have been cited & 5529 \\
Number of countries of author affiliation & 10 \\
Number of host institutions & 9 \\
Number of papers with a CARTA fellow as first & $318(41 \%)$ \\
author & \\
Authorship teams & $29(3.6 \%)$ \\
Single-authored publications (\%) & $434(61.5 \%)$ \\
Publications with 2-5 authors (\%) & $246(34.9 \%)$ \\
Publications with $\geq 5$ authors (\%) & $5(s d: 4)$ \\
Mean number of authors per publication & \\
Research approach & $6 \%$ \\
Mixed methods & $12 \%$ \\
Qualitative & $72 \%$ \\
Quantitative & $10 \%$ \\
Review &
\end{tabular}

such as environmental health $(6.5 \%)$, violence and injuries (4.4\%), and food security and nutrition (2.4\%).

Approximately $28 \%$ of the publications in the different health priority areas listed in Table 1 were from studies that targeted females exclusive or a combination of females and males (67.9\%) and few focused on males only (4.1\%). The few males only publications were predominantly on infectious diseases (31.3\%) and sexual and reproductive health (31.3\%). By age group, $68.2 \%$ of the studies targeted people aged 20 years old and above, about $18.4 \%$ of the studies targeted children under 10 years old and $13.5 \%$ of the studies targeted adolescents (10-19 year olds). Of note is that mental health and substance abuse publications were only among people aged 20 years old and above, with none among adolescents and children under 10 years old.

\section{Infectious diseases}

The 135 infectious disease publications focused on prevalent diseases common in Africa, including HIV and AIDS (48.1\%), followed by malaria (25.9\%), TB (11.9\%), and other STIs (6.7\%), as shown in Fig. 3. There was minimal research in the areas of co-infections $(5.9 \%)$ and neglected tropical diseases (NTDs) (1.5\%). The majority of the infectious disease publications targeted females and males together (79.6\%), followed by females only $(15.7 \%)$ and males only (4.6\%). By age group, most of the studies (67.4\%) targeted people aged 20 years old and above, followed by children under 10 years old (18.6\%) and for adolescents aged 10 to 19 years old $(13.5 \%)$.

\section{Maternal and child health (MCH)}

The publications on $\mathrm{MCH}$ comprised of 80 papers constituting $14.7 \%$ of the research output. The main topics of focus in this priority area were maternal and child mortality $(27.5 \%)$, antenatal care $(20.0 \%)$, and immunisation (12.5\%). Obstetric complications, and child growth and development contributed $7.5 \%$ to this category, followed by childhood illnesses (6.3\%) as shown in Fig. 4. The majority of the publications on $\mathrm{MCH}$ targeted females and males together (53.3\%), followed by females 


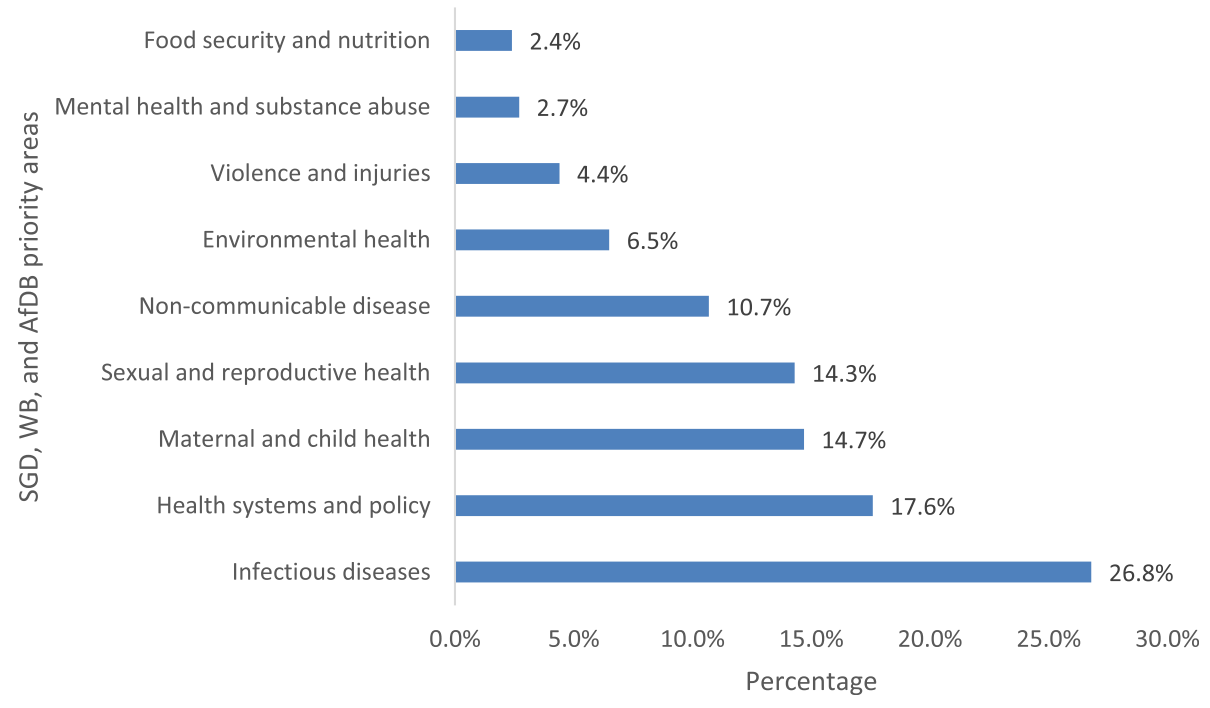

Fig. 2 Percentage of CARTA publications by research priority area

only (41.9\%) and males only (4.8\%). By age group most of the studies targeted people aged 20 years old and above $(52.4 \%)$ followed by children under 10 years old (46.3\%) and adolescents aged 10 to 19 years old (1.6\%).

\section{Sexual and reproductive health (SRH)}

Overall, 79 publications addressed SRH issues (17.7\% of total publications). More than a quarter of the publications on this topic were on adolescent sexual health (26.6\%), followed by culture and sexuality (17.7\%) and family planning (14.0\%). Research on fertility and abortion constituted 12.7 and $11.4 \%$, respectively. Other areas under SRH included risky sexual behaviours and transactional sex (Fig. 5). The majority of the publications on SRH targeted females only (53.9\%), followed by females and males together (38.5\%), and males only (7.7\%). By age group, most of the studies targeted people aged 20 years old and above (64.4\%) followed by adolescents at $35.6 \%$.

\section{Health systems and policy}

The majority of health systems and policy publications ( $n=97)$ dealt with health system strengthening (76.0\%) followed by the use of mHealth solutions (10.4\%) and health economics (8.3\%).

\section{Non-communicable diseases (NCDs)}

Fifty-nine publications (10.7\%) of the total publications focused on NCDs. Half of the research output classified under NCDs was on cancers (51.0\%), followed by cardiovascular diseases (27.0\%), diabetes (16\%), and obesity $5.0 \%$. Approximately $5.0 \%$ of the publications on NCDs were among children and adolescents while 95\% were among people aged 20 years old and above.

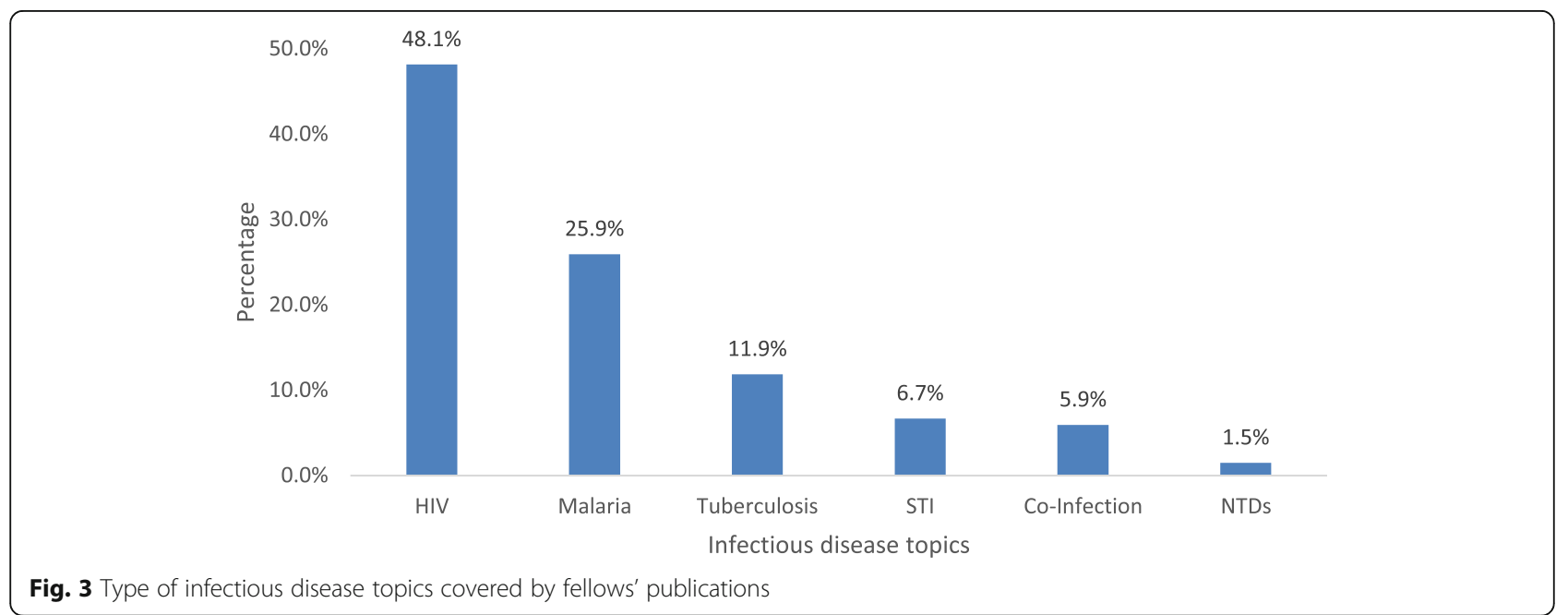




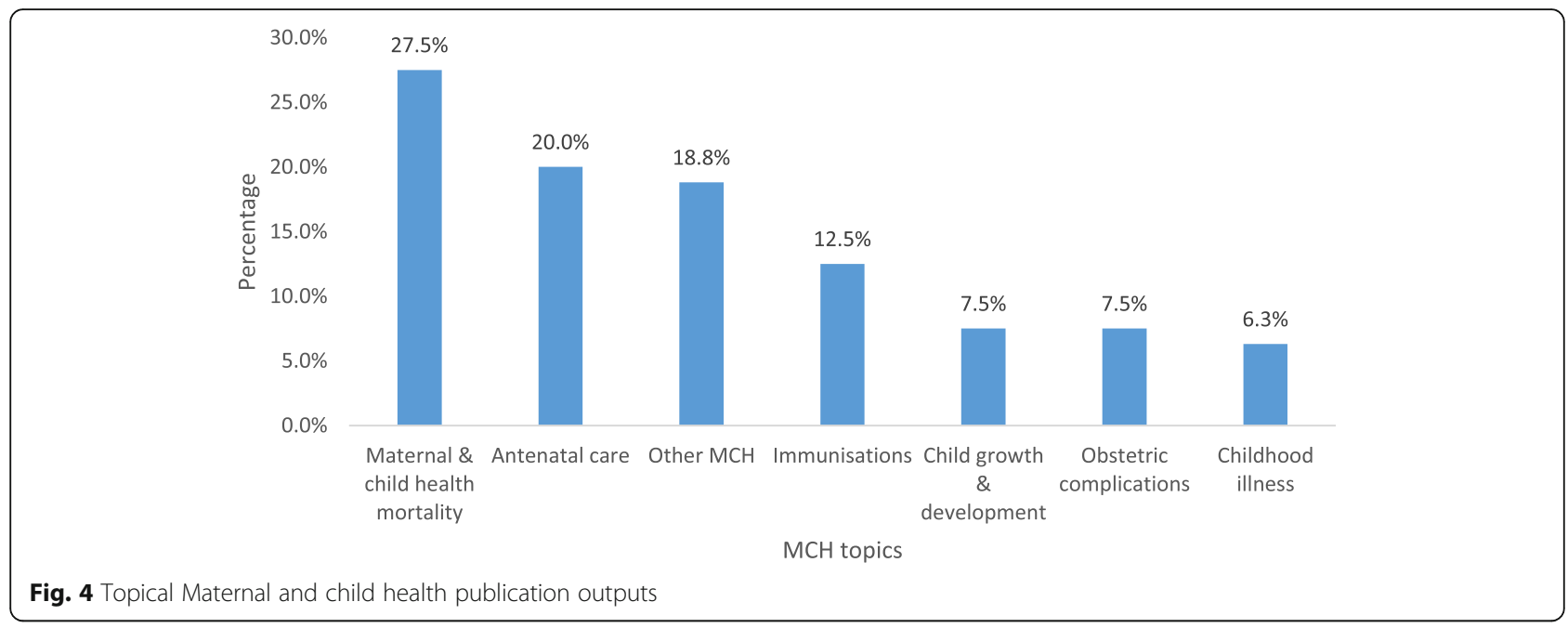

\section{Violence and injuries}

A total of $24(4.4 \%)$ of the total publications were on violence and injuries. Most of these publications were on intimate partner violence $(75.0 \%)$, and the rest were on bullying (12.5\%) and general injuries (12.5\%). While similar proportions of publications on violence and injuries were conducted among females only and males and females combined at $47 \%$ respectively, about $6 \%$ of the studies focused on males only.

\section{Environmental health}

About $6.5 \%$ of the total publications were on environmental health. Most of the publications on environmental health dealt with environmental impact assessment (45\%) followed by historical public health challenges such as water and sanitation (37.1\%) and indoor air pollution (20\%).

\section{Funding sources}

Finally, about $50 \%$ of the published papers had information on additional sources of direct and indirect financial support and we counted at least 160 different sources of support. The most commonly reported sources of additional support were National Institute of Health (12.7\%), United States Agency for International Development (4.3\%), Wellcome Trust (3.8\%), National Research Foundation (3.6\%) and the South African Medical Research Council (3.3\%).

\section{Discussion}

Building and sustaining research capacity has been advocated as a leading strategy to overcome health disparities in Africa [25]. Our analysis showed a steady increase in the annual number of articles published by CARTA fellows in the 8 years studied, a finding that has been

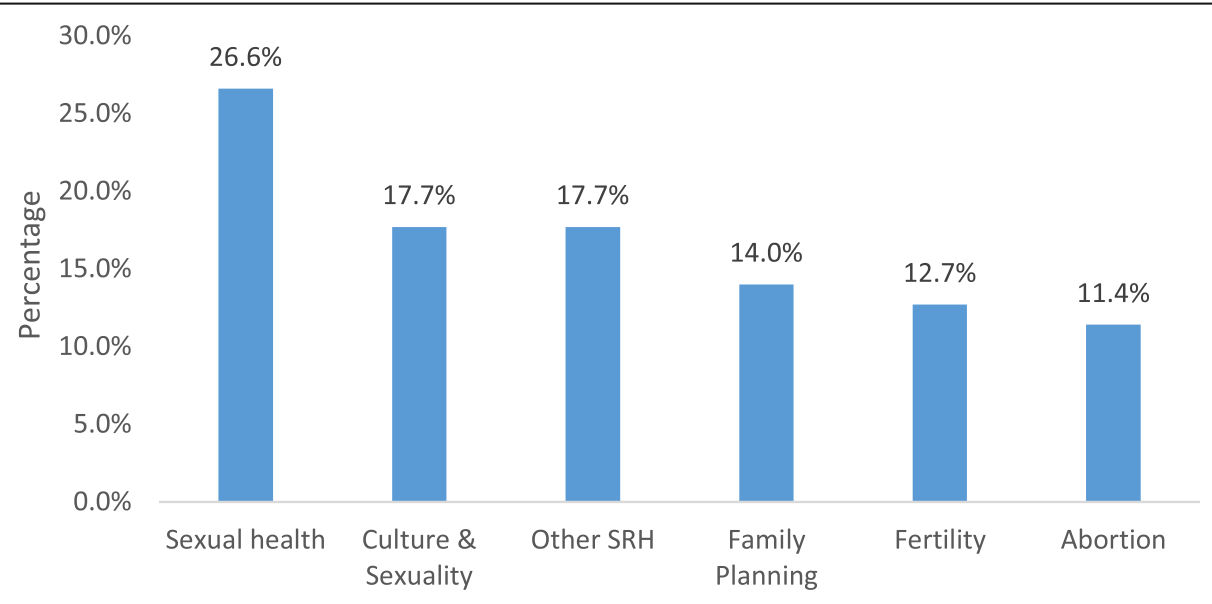

Sexual and reproductive health topics

Fig. 5 Sexual and reproductive health publications 
reported elsewhere [27]. The year-on-year increase in publications is likely to be as a result of the corresponding increase in the number of CARTA fellows each year. In 2011 there were 20 fellows in the programme and by 2018, 185 fellows had been admitted in the fellowship. The areas of study were likely a reflection of the increased global response to infectious diseases such as HIV and AIDS, TB and malaria through funding programs such as the Global Fund and the investments by the National Institute of Health and the United States Agency for International Development reported in the fellows' publications. Increased funding in these areas may have influenced the selection of research topics by CARTA fellows. Studies have reported that HIV/AIDS, malaria and tuberculosis (TB) continue to attract the greatest investment from external funders, a trend that influences current research being conducted in sub-Saharan Africa [16, 28].

In our analysis, the subject areas addressed by CARTA $\mathrm{PhD}$ fellows are mostly aligned with the SDGs, World Bank and AfDB priority areas, addressing research gaps in infectious diseases, maternal and child health, and sexual and reproductive health. These research areas are in line with the burden of disease and health system priorities in the region. Studies show that $90 \%$ of children who die from malaria are from sub-Saharan Africa (SSA), and 72\% of deaths in the region are attributed to infectious diseases including HIV/AIDS, TB, and Malaria, and from complications related to pregnancy and childbirth [26].

Despite the increasing number of NCDs including cancers, diabetes and hypertension - that are now cooccurring alongside infectious chronic diseases (such as HIV and TB) [29], findings from this study show less research is conducted in this field. In addition, in the face of high burden of neglected tropical diseases, such as helminth infections, hookworms, and other protozoa amongst the poorest in SSA [30], our analysis showed that while this is being studied, very few papers were found in this area. The same trend was observed in infectious diseases such as hepatitis $B$ and $C$, despite the substantial burden that these diseases have in Africa [31, 32]. Notably, only a few fellows researched violence and injury. This finding concurred with earlier research indicating that despite violence and injuryrelated morbidity being at the top of the list of disease burden in Africa, the field remains under-researched [33]. In addition, there were no studies on mental health and substance abuse among children and adolescents; this is in spite of their correlation and burden in the continent [34, 35]. In light of these findings, we recommend that African universities broaden their research priorities in tandem with the change in disease burden taking place in Africa. Contextually focused research would provide appropriate evidence-based information to guide policies and decisions aimed at addressing disease burden and future epidemics in Africa [2].
Our analyses also show that most articles were published by fellows from or affiliated to consortium universities in Kenya, Nigeria, and South Africa. The three countries are also home to five of the nine host institutions in the consortium. This finding is similar to earlier studies that revealed that health research productivity in Africa is skewed, with countries like South Africa, Nigeria, and Kenya contributing more than half of all research papers indexed in PubMed between 2000 and 2014 [17]. This could also be due to differences in economic development and education levels (including epidemiology or public health programmes), which vary widely between and even within countries $[11,26]$. Thus, it is paramount to keep developing research capacity in partner institutions with low research output by ensuring an enabling environment for conducting research and training more $\mathrm{PhDs}$ in such institutions.

The increase in the number of articles published by CARTA fellows contributes to improved health research output of African academic and research institutions. Whereas externally supported researchers from subSaharan Africa have often undertaken postgraduate degrees at institutions in high-income countries [9], CARTA has demonstrated a mechanism to increase $\mathrm{PhD}$ training in African institutions. Local enrolment is supplemented by additional PhD training - CARTA's Joint Advanced Seminars (JAS) to ensure $\mathrm{PhD}$ students are internationally competitive and also orients them towards locally relevant research [36]. Such initiatives could be supported by African governments (in respective countries) by prioritising research funding and considering the needs of young researchers in Africa. Only if African governments invest in young researchers will the continent be able to come up with innovations that are relevant to solving the public health problems affecting the population of the region.

\section{Limitations}

We acknowledge some limitations of our study. Although it reports on the number of publications by CARTA fellows, it lacks information on the impact these publications have on policy implementation. This study relied on self-reporting of publications to the CARTA secretariat alone; publication outputs not reported were not included. While we recognise the number of times fellows' publications have been cited, we did not ascertain how much of it were self-citations. Lastly, CARTA fellows are only a small subset of all PhDs in any institution and this report is not a reflection of the full range of topics studied at the institutions.

\section{Conclusions}

This study demonstrates the full range of topics that CARTA fellows are researching on. The evaluation has 
shown that investments by CARTA in supporting doctoral training at African training institutions has been beneficial to the region as the programme has provided the $\mathrm{PhD}$ fellows sufficient motivation and skills to publish their research in the broad fields of public and population health. There is a need to keep developing research capacity in countries with low research output by training more $\mathrm{PhDs}$ in such institutions and by facilitating enabling environments for research. Further and broader exploration of nature and the drivers of public and population health research output remains an imperative to address gaps, promote alignment and sustainability of public health training, research and practice in sub-Saharan Africa.

\begin{abstract}
Abbreviations
AAS: African Academy of Science; AESA: Accelerating Excellence in Science in Africa; AfDB: Africa Development Bank; AFRO: African Region; AIDS: Acquired Immunodeficiency Syndrome; APHRC: African Population and Health Research Centre; CARTA: Consortium for Advanced Research Training in Africa; CDC: Centre for Disease Control; DAAD: Deutscher Akademischer Austauschdienst; DELTAS: Developing Excellence in Leadership, Training and Science; HIV: Human Immunodeficiency Virus; IQR: Interquartile Range; MCH: Maternal and Child Health; MDGs: Millennium Development Goals; NCDs: Non-Communicable Diseases; NEPAD: New Partnership for Africa's Development; NTD: Neglected Tropical Disease; SRH: Sexual and Reproductive Health; SDG: Sustainable Development Goals; TB: Tuberculosis; WB: World Bank; WHO: World Health Organization
\end{abstract}

\section{Acknowledgements}

We acknowledge all the CARTA funders.

\section{Authors' contributions}

JOI Conceptualised the study, analysed data and drafted the manuscript; ENB analysed data and drafted the manuscript; TJB Conceptualised the study, analysed data and drafted the manuscript; UD, OF, HW, AA, EO,FK, DC, EG reviewed and commented on the manuscript; SF Conceptualised the study, provided funding, commented on the manuscript. All authors have read and approved the manuscript.

\section{Funding}

This study was funded through the Consortium for Advanced Research Training in Africa (CARTA). CARTA is jointly led by the African Population and Health Research Center and the University of the Witwatersrand and funded by the Carnegie Corporation of New York (Grant No--B 8606.R02), Sida (Grant No:54100113), the DELTAS Africa Initiative (Grant No: 107768/Z/15/Z) and Deutscher Akademischer Austauschdienst (DAAD). The DELTAS Africa Initiative is an independent funding scheme of the African Academy of Sciences (AAS)'s Alliance for Accelerating Excellence in Science in Africa (AESA) and supported by the New Partnership for Africa's Development Planning and Coordinating Agency (NEPAD Agency) with funding from the Wellcome Trust (UK) and the UK government. The statements made and views expressed are solely the responsibility of the Fellow.

\section{Availability of data and materials}

The data that support the findings of this study are available from the corresponding author on reasonable request.

\section{Ethics approval and consent to participate}

$$
\text { Not applicable. }
$$

\section{Consent for publication}

Not applicable.

\section{Competing interests}

The authors declare that they have no competing interests.

\section{Author details}

${ }^{1}$ School of Public Health, Faculty of Health Sciences, University of the Witwatersrand, Johannesburg, South Africa. ${ }^{2}$ South African Medical Research Council Developmental Pathways for Health Research Unit (DPHRU), School of Clinical Medicine, Faculty of Health Sciences, University of the Witwatersrand, 27 St Andrews Road, Parktown, Johannesburg, South Africa. ${ }^{3}$ School of Governance, University of Rwanda, Kigali, Rwanda. ${ }^{4}$ Department of Sociology, University of Ibadan, Ibadan, Nigeria. ${ }^{5}$ African Population and Health Research Centre, Nairobi, Kenya. ${ }^{6}$ Department of Health Promotion and Education, University of Ibadan, Ibadan, Nigeria.

Received: 12 February 2020 Accepted: 18 June 2020

Published online: 29 June 2020

\section{References}

1. Agyei-Mensah S, De-Graft AA. Epidemiological transition and the double burden of disease in Accra, Ghana. J Urban Heal. 2010;87(5):879-97. https:// doi.org/10.1007/s11524-010-9492-y.

2. Mathers $C D$, Loncar D. Projections of global mortality and burden of disease from 2002 to 2030. PLoS Med. 2006;3:e442. https://doi.org/10.1371/journal. pmed.0030442.

3. Nyaaba GN, Stronks K, De-Graft Aikins A, Kengne AP, Agyemang C. Tracing Africa's progress towards implementing the non-communicable diseases global action plan 2013-2020: a synthesis of WHO country profile reports. BMC Public Health. 2017;17(1):1-13. https://doi.org/10.1186/s12889-017-4199-6.

4. Kirigia JM, Barry SP. Health challenges in Africa and the way forward. Int Arch Med. 2008;1:27. https://doi.org/10.1186/1755-7682-1-27.

5. Sanders D, Chopra M. Key challenges to achieving health for all in an inequitable society: the case of South Africa. Am J Public Heal. 2006;96:73-8. https://doi.org/10.2105/AJPH.2005.062679.

6. Koon A, Nambiar D, Rao DK. Embedding of research into decision-making processes. Geneva: Alliance for Health Policy and Systems Research, WHO; 2012. https://www.who.int/alliance-hpsr/alliancehpsr_background paper embedding research. Accessed 21 Nov 2019.

7. Bennett S, Agyepong IA, Sheikh K, Hanson K, Ssengooba F, Gilson L. Building the field of health policy and systems research: an agenda for action. PLoS Med. 2011;8:e100108110. https://doi.org/10.1371/journal.pmed. 1001079.

8. Charon D, Mohamed A, Lucia S. Africa generates less than $1 \%$ of the world's research; data analytics can change that. Elsevier. 2018. https://www.elsevier. com/connect/africa-generates-less-than-1-of-the-worlds-research-dataanalytics-can-change-that. Accessed 7 Feb 2020.

9. Morel T, Maher D, Nyirenda T, Olesen FO. Strengthening health research capacity in sub-Saharan Africa: mapping the 2012-2017 landscape of externally funded international postgraduate training at institutions in the region. Glob Health. 2018;14(1):1-10. https://doi.org/10.1186/s12992-0180395-0.

10. Fonseca PB, Albuquerque PC, Noyons E, Zicker F. South-south collaboration on HIV/AIDS prevention and treatment research : when birds of a feather rarely flock together. Glob Health. 2018;14:1-12. https://doi.org/10.1186/ s12992-018-0341-1.

11. Langer A, Diaz-Olavarrieta C, Berdichevsky K, Villar J. Why is research from developing countries underrepresented in international health literature, and what can be done about it? Bull World Heal Organ. 2004;82:802-3.

12. Chu KM, Jayaraman S, Kyamanywa P, Ntakiyiruta G. Building research capacity in Africa: equity and Global Health collaborations. PLoS Med. 2014; 11:e1001612. https://doi.org/10.1371/journal.pmed.1001612.

13. NEPAD Planning and Coordinating Agency (NPCA). African innovation outlook 2014. Pretoria: 2014.

14. Neupane B. A more developmental approach to science. UNESCO science report: towards 2030. 2015. https://en.unesco.org/unesco_science_report. Accessed Nov 2019.

15. Minor JT. African higher education: an international reference handbook. Rev High Educ. 2004;27(4):585-6.

16. Nachega JB, Uthman OA, Ho YS, Lo M, Anude C, Kayembe P, et al. Current status and future prospects of epidemiology and public health training and research in the WHO African region. Int J Epidemiol. 2012;41(6):1829-46. https://doi.org/10.1093/ije/dys189.

17. Uthman OA, Wiysonge CS, Ota MO, Nicol M, Hussey GD, Ndumbe PM, et al. Increasing the value of health research in the WHO African region beyond 2015 - reflecting on the past, celebrating the present and building the 
future: a bibiliometric analysis. BMJ Open. 2015;5(3):e006340. https:/doi.org/ 10.1136/bmjopen-2014-006340.

18. Ejughemre U. Donor support and the impacts on health system strengthening in sub-Saharan Africa: assessing the evidence through a review of the literature. Am J Public Heal Res. 2013;1 (7):146-51. https://doi. org/10.12691/ajphr-1-7-1.

19. Carnegie Corporation of New York. Carnegie Corporation Continues Commitment to Supporting Higher Education in sub-Saharan Africa. 2009. https:/www.carnegie.org/news/articles/carnegie-corporation-continuescommitment-to-supporting-higher-education-in-sub-saharan-africa/. Accessed 6 Feb 2020.

20. Fonn S, Hu J, Igumbor J, Gatoto D, Muula A, Ezeh A. Quantifying the cost of in-kind contributions to a multi-donor funded research capacity building programme: the case of the consortium for advanced research training in Africa (CARTA). BMJ Glob Heal. 2020;5:e002286. https://doi.org/10.1136/ bmjgh-2020-002286.

21. African Union Commission. Agenda 2063: The Africa We Want: A Shared Strategic Framework for Inclusive Growth and Sustainable Development. https://www.un.org/en/africa/osaa/pdf/au/agenda2063. 2015. Accessed 10 Oct 2019.

22. Welcome. African institutions lead international consortia in $£ 30$ million initiative. 2009. https://wellcome.ac.uk/funding. Accessed 6 Feb 2020.

23. The African Academy of Sciences. Developing Excellence in Leadership, Training and Science in Africa (DELTAS Africa). https://www.aasciences. africa/aesa/programmes/developing-excellence-leadership-training-andscience-africa-deltas-africa\#tabout-the-aas. Accessed 6 Feb 2020.

24. African Union. Second session of the specialised technical committee on health, population and drug control (STC-HPDC-2) Addis Ababa, Ethiopia 20-24 March 2017. 2017. https://au.int/en/newsevents/20170320/secondsession-specialised-technical-committee-health-population-and-drug. Accessed 12 Oct 2019

25. Fonn S. African PhD research capacity in public health: raison d'etre and how to build it. In Global forum update on research for health (Vol. 3, pp. 80-83). Geneva: Global Forum for Health Research; 2006

26. Ezeh AC, Izugbara CO, Kabiru CW, Fonn S, Kahn K, Manderson L, et al. Building capacity for public and population health research in Africa: the consortium for advanced research training in Africa (CARTA) model. Glob Health Action. 2010;3(1):1-7. https://doi.org/10.3402/gha.v3i0.5693.

27. Kabiru CW, Izugbara CO, Wairimu J, Amendah D, Ezeh AC. Strengthening local health research capacity in Africa: the African doctoral dissertation research fellowship program. Pan Afr Med J. 2014;17(Suppl 1):1. https://doi. org/10.11694/pamj.supp.2014.17.1.3729.

28. Fitchett JR, Head MG, Atun R. Infectious disease research investments follow colonial ties: questionable ethics. Int Health. 2014;6(1):74-6. https://doi.org/ 10.1093/inthealth/iht036

29. Oni T, Youngblood E, Boulle A, McGrath N, Wilkinson RJ, Levitt N. Patterns of HIV, TB, and non-communicable disease multi-morbidity in peri-urban South Africa-a cross sectional study. BMC Infect Dis. 2015;15(1):1. https://doi. org/10.1186/s12879-015-0750-1.

30. Hotez PJ, Kamath A. Neglected tropical diseases in sub-Saharan Africa: review of their prevalence, distribution, and disease burden. PLoS Negl Trop Dis. 2009;3(8):2-11. https://doi.org/10.1371/journal.pntd.0000412.

31. Spearman CW, Afihene M, Ally R, Apica B, Awuku Y, Cunha L, et al. Hepatitis $B$ in sub-Saharan Africa: strategies to achieve the 2030 elimination targets. Lancet Gastroenterol Hepatol. 2017;2(12):900-9. https://doi.org/10.1016/ S2468-1253(17)30295-9.

32. Sonderup MW, Afihene M, Ally R, Apica B, Awuku Y, Cunha L, et al. Hepatitis $C$ in sub-Saharan Africa: the current status and recommendations for achieving elimination by 2030. Lancet Gastroenterol Hepatol. 2017;2(12): 910-9. https://doi.org/10.1016/S2468-1253(17)30249-2.

33. Diamond MB, Dalal S, Adebamowo C, Guwatudde D, Laurence C, Ajayi IO, et al. Prevalence and risk factor for injury in sub-Saharan Africa: a multicountry study. Inj Prev. 2018;24(4):272-8. https://doi.org/10.1136/ injuryprev-2016-042254.

34. Flisher AJ, Dawes A, Kafaar Z, Lund C, Sorsdahl K, Myers B, et al. Child and adolescent mental health in South Africa. J Child Adolesc Ment Health. 2012;24(2):149-61. https://doi.org/10.2989/17280583.2012.735505.

35. Owen JP, Baig B, Abbo C, Baheretibeb Y. Child and adolescent mental health in sub-Saharan Africa: a perspective from clinicians and researchers. BJPsych Int. 2016;13(2):45-7. https://doi.org/10.1192/s2056474000001136.
36. Fonn S, Egesah O, Cole D, Griffiths F, Manderson L, Kabiru C, et al. Building the capacity to solve complex health challenges in sub-Saharan Africa: CART A's multidisciplinary PhD training. Can J Public Heal. 2016;107(4-5):e381-6. https://doi.org/10.17269/cjph.107.5511.

\section{Publisher's Note}

Springer Nature remains neutral with regard to jurisdictional claims in published maps and institutional affiliations.

\section{Ready to submit your research? Choose BMC and benefit from:}

- fast, convenient online submission

- thorough peer review by experienced researchers in your field

- rapid publication on acceptance

- support for research data, including large and complex data types

- gold Open Access which fosters wider collaboration and increased citations

- maximum visibility for your research: over $100 \mathrm{M}$ website views per year

At BMC, research is always in progress.

Learn more biomedcentral.com/submissions 